\title{
Diabetic Foot Ulcer is a Significant Predictor of Silent Myocardial Ischemia in Women with Type 2 Diabetes
}

Yaser Jenab ${ }^{1}$, Afsaneh Morteza ${ }^{1,2}$, Younes Nozari ${ }^{1}$, Alireza Farokhian ${ }^{1}$, Jalil Majd Ardekani ${ }^{3}$ and Manouchehr Nakhjavani2*

Department of Cardiology, Imam Hospital Complex, Tehran University of Medical Sciences, Tehran, Iran

${ }^{2}$ Endocrinology and Metabolism Research Center (EMRC), Vali-Asr Hospital, Tehran University of Medical Sciences, Tehran, Iran

${ }^{3}$ Department of Nuclear Medicine, Tehran Heart Center, Tehran University of Medical Science, Tehran, Iran

\begin{abstract}
Introduction: Screening silent myocardial ischemia in asymptomatic patients with type 2 diabetes is still controversial. The purpose of the present study was to define the value of diabetic foot ulcer (DFU) in the prediction of silent myocardial ischemia in asymptomatic men and women with type 2 diabetes.

Methods: We performed a cross sectional study on 150 diabetic patients with DFU, as cases, and 90 diabetic patients, without the history of any type of DFU, as controls. Presence of silent myocardial ischemia was assessed by dipyridamole single-photon emission- computed tomography myocardial perfusion (SPECT) imaging with thallium-201.

Results: Patients with DFU had longer diabetes duration, higher serum $\mathrm{HbA1C}$, and lower serum high density lipoprotein cholesterol levels, compared to patients without DFU. There were a greater number of women with silent myocardial ischemia $(28 / 63(44.4 \%)$ vs. $28 / 87(32.2 \%)$; $p<0.05)$ in patients with DFU compared to men. There were a greater number of men with silent myocardial ischemia compared to women $(10 / 47(21.3 \%)$ vs. $2 / 43(4.7 \%) ; p<0.05$ in patients without DFU. Logistic regression analysis demonstrated that the odds ratio of having silent myocardial ischemia was 2.96 in women with DFU, 0.18 in women without DFU and 1.75 in men with DFU compared to men without DFU, adjusting for $\mathrm{HbA1c}, \mathrm{HDL}-\mathrm{C}$ and diabetes duration.
\end{abstract}

Discussion: Women with DFU are at an increased risk of having silent myocardial ischemia, compared to male counterparts.

Keywords: Diabetic foot ulcer; SPECT; Scan sex characteristics

Abbreviation: BMI: Body Mass Index; SPECT: Single Photon Emission Computed Tomography; TG: Triglyceride; HDL-C: High Density Lipoprotein Cholesterol; LDL-C: Low Density Lipoprotein Cholesterol; SEM: Standard Error of Mean

\section{Introduction}

Silent myocardial ischemia is more frequent among type 2 diabetic patients than in non diabetic matched controls [1]. In addition silent myocardial ischemia has a higher predictive value for cardiovascular events than the classical cardiovascular risk factors [2]. There is increasing evidence that intensive medical therapy indicated in diabetic patients at high risk of cardiovascular disorders is as effective as invasive revascularization [3]. Consistently silent myocardial ischemia in patients with type 2 diabetes may reverse over time [4]. There is $80 \%$ risk reduction of cardiac events by screening of unknown asymptomatic coronary artery disease in subjects with type 2 diabetes at high cardiovascular risk [5]. So it is advisable to detect coronary artery disease at the silent stage to prevent cardiac events. However screening all patients with type 2 diabetes for silent ischemia would collapse the health care system. Recent studies try to establish clinical markers for the prediction of silent myocardial ischemia in patients with type 2 diabetes.

Diabetic retinopathy and urinary albumin excretion are known predictors of silent myocardial ischemia, which have a stronger predictive value in men with type 2 diabetes $[6,7]$. To date we are unaware of any study demonstrating the value of diabetic foot ulcer (DFU) in the prediction of silent myocardial ischemia among patients with type 2 diabetes. The diversity in risk factors for development of coronary heart disease such as dyslipidemia and albuminuria between men and women with type 2 diabetes may had confounded previous studies $[8,9]$. The purpose of the present study was to define the value of $\mathrm{DFU}$ in the prediction of silent myocardial ischemia in asymptomatic men and women with type 2 diabetes.

\section{Method}

We performed a cross sectional study on 150 diabetic patients with DFU, as cases and 90 age and body mass index (BMI) matched diabetic patients without the history of any type of diabetic foot disease as controls. Participants were recruited from diabetes clinic of Vali Asr hospital affiliated with Tehran University of Medical Science from January 2008 to December 2010. Diabetes was diagnosed according to the criteria of the American Diabetes Association [10]. Exclusion criteria were type 1 diabetes, acute or chronic renal failure, glumerulonephritis, angina pectoris or angina equivalent symptoms, electrocardiographic evidence of Q-wave myocardial infarction, ischemic ST-segment or $\mathrm{T}$-wave changes, complete left bundle branch block, indications for

*Corresponding author: Manouchehr Nakhjavani, MD Professor of Endocrinology, Endocrinology and Metabolism Research Center (EMRC), ValiAsr Hospital, Tehran University of Medical Sciences, Tehran, Iran, Tel: (+9821)8841791; Fax: (+9821)-64432466; E-mail: nakhjavanim@tums.ac.ir

Received October 16, 2011; Accepted December 15, 2011; Published Decembe 20, 2011

Citation: Jenab Y, Morteza A, Nozari Y, Farokhian A, Ardekani JM, et al. (2011) Diabetic Foot Ulcer is a Significant Predictor of Silent Myocardial Ischemia in Women with Type 2 Diabetes. J Diabetes Metab 2:161. doi:10.4172/21556156.1000161

Copyright: ( 2011 Jenab Y, et al. This is an open-access article distributed unde the terms of the Creative Commons Attribution License, which permits unrestricted use, distribution, and reproduction in any medium, provided the original author and source are credited. 
stress testing, congestive heart failure, acute infections, pregnancy, diabetic ketoacidosis, non-ketonic hyperosmolar diabetes, history of myocardial infarction, heart failure, coronary revascularization, CCU admission, coronary angiography, thyroid disorders and hospital admission in recent 3 months. None of the studied women were on hormone replacement therapy. DFU was defined as a full-thickness skin defect that required $>14$ days to heal [11]. The patients presented an ulcer for the first time, and all were unilateral. The wound were classified according to the wound classification system of the University of Texas [12]. Eighty seven percent (130/150) were superficial ulcers without or with infection/ischemia, $9 \%(14 / 150)$ were deep ulcers to tendon or capsule and $4 \%(6 / 150)$ had wounds penetrating the bone or joint. All the patients underwent color Doppler ultrasound study of the limb and (51/150) $34 \%$ of them had ischemic problems.

Moreover all the patients had clinical neuropathy of the limb. Demographic and anthropometric data including age, sex, duration of diabetes, height, weight in light clothing and blood pressure in sitting position were recorded. Blood pressure was re measured twice after 5 minutes average. The BMI $\left(\mathrm{Kg} / \mathrm{m}^{2}\right)$ was calculated according to the Quetelet formula. All participants gave written informed consent before participation. The research was carried out according to the principles of the declaration of Helsinki; the local ethics review committee of Tehran University of Medical Science approved the study protocol.

\section{Single photon emission computed tomography (SPECT)}

We studied the presence of silent myocardial ischemia with dipyridamole single photon emission computed tomography (Dipyridamole SPECT) in cases and controls. Rest-dipyridamole SPECT is the preferred method for the detection of silent myocardial ischemia in patients with type 2 diabetes [13]. Moreover, cases with the presence of DFU were unable to undergo exercise SPECT. After 30 minutes resting injection of $8 \mathrm{mCi}$ of 99Tc tetrofosmin (Myoview, Amersham,UK) resting images were obtained using ADAC Forte dual-head gamma camera (Philips Medical Systems, Eindhoven, The Netherlands), to acquire 64 views over $180^{\circ}$, using a step and shoot protocol. Three hourslater, patients underwent a standard Dipyridamole stress protocol $(0.56 \mathrm{mg} / \mathrm{kg}$ given intravenously over four minutes) [13]. Stress phase imaging was performed 30-60 min following tracer injection $25 \mathrm{mCi}$ of dipyridamole at peak pharmacological stress (64 views over 180).

\section{Blood samples}

Blood samples were collected after almost 12 hours of fasting and, serum creatinine, fasting blood sugar, total cholesterol, triglyceride (TG), high density lipoprotein cholesterol (HDL-C), low density lipoprotein cholesterol (LDL-C) and HbA1C were measured. Glucose measurements (intra-assay coefficient of variants [CV] 2.1\%, interassay CV 2.6\%) were carried out using the glucose oxidase method. Creatinine was measured using calibrated Jaffe method (Parsazmoon, Karaj, Iran). Cholesterol, HDL-C, LDL-C and TG were determined using direct enzymatic methods (Parsazmun, Karaj, Iran). HbA1C was estimated by High-Pressure Liquid Chromatography (HPLC) Method. Serum creatinine was measured using direct colorimetric method. White Blood Cell (WBC) count was measured using Sysmex XT-1800 cell counter, Japan.

\section{Statistical analysis}

The statistical package SPSS 16 for windows (Chicago, Illinois, USA), was used for analysis. Quantitative variables are presented as mean \pm standard error of mean (SEM). Qualitative variables are presented as number and percent. Independent sample $t$ test (for quantitative variables) and Chie square test (for qualitative variables) were employed to compare cases and controls. To provide a measure of association of DFU and the presence of silent myocardial ischemia in men and women, the patients were stratified according to gender. Chie square was employed for the comparison of categorical variables (using odds ratio) between men and women. Logistic regression analysis was employed to predict the odds ratio of having silent myocardial ischemia in the studied groups (women with DFU, men with DFU and women without DFU) compared to men without DFU, adjusting for HbAlc, HDL-C and diabetes duration. Significance was set at $\mathrm{p}<0.05$.

\begin{tabular}{|c|c|c|c|}
\hline & Without diabetic foot ulcer $(n=90)$ & With diabetic foot ulcer $(n=150)$ & $P$ value \\
\hline Age (years) & $58.8 \pm 1.09$ & $56.1 \pm 1.97$ & NS \\
\hline Diabetes Duration (years) & $8.2 \pm 0.97$ & $13.23 \pm 1.26$ & $<0.001$ \\
\hline Female (n, \%) & $43(47.8 \%)$ & $63(42.0 \%)$ & NS \\
\hline BMI $\left(\mathrm{kg} / \mathrm{m}^{2}\right)$ & $27.4 \pm 0.75$ & $28.27 \pm 0.94$ & NS \\
\hline Systolic blood pressure (mmHg) & $145.3 \pm 4.50$ & $139.03 \pm 4.97$ & NS \\
\hline Diastolic Blood Pressure (mmHg) & $87.45 \pm 1.96$ & $84.61 \pm 2.97$ & NS \\
\hline HbA1C (\%) & $7.91 \pm 0.26$ & $8.95 \pm 0.37$ & $<0.05$ \\
\hline Triglyceride (mg/dl) & $165.0 \pm 9.61$ & $199.68 \pm 26.05$ & NS \\
\hline Cholesterol (mg/dl) & $191.0 \pm 6.163$ & $187.04 \pm 6.96$ & NS \\
\hline LDL-C (mg/dl) & $106.65 \pm 5.64$ & $102.97 \pm 5.86$ & NS \\
\hline HDL-C (mg/dl) & $50.15 \pm 2.24$ & $42.12 \pm 2.03$ & $<0.05$ \\
\hline White Blood Cell (per $\mu \mathrm{L})$ & $9920.0 \pm 634.35$ & $1020.76 \pm 991.618$ & NS \\
\hline Creatinine (mg/dl) & $1.04 \pm 0.048$ & $1.3 \pm 0.20$ & NS \\
\hline Silent myocardial ischemia & $12(13.3 \%)$ & $56(37.3 \%)$ & $<0.001$ \\
\hline
\end{tabular}

Groups are matched for age and BMI. Quantitative variables are expressed as Mean \pm Standard Error of mean (SEM); otherwise number and percent. BMI, body mass index; HDL-C, high density lipoprotein cholesterol; LDL-C; low density lipoprotein cholesterol; NS: none significant

Table 1: Presenting the primary characteristics of participants. 
Citation: Jenab Y, Morteza A, Nozari Y, Farokhian A, Ardekani JM, et al. (2011) Diabetic Foot Ulcer is a Significant Predictor of Silent Myocardial Ischemia in Women with Type 2 Diabetes. J Diabetes Metab 2:161. doi:10.4172/2155-6156.1000161

Page 3 of 5

\section{Results}

Demographic, biochemical and clinical characteristics of participants are illustrated in table 1 . The frequency of insulin therapy was $20 \%(30 / 150)$ in patients with DFU and $23 \%(21 / 90)$ in patients without DFU, 46\% (110/240) of the patients were on statin therapy and $52 \%(125 / 240)$ were on anti hypertensive treatment. Patients with DFU had longer diabetes duration, a higher serum $\mathrm{HbA1C}$ and a lower a serum HDL levels compared to patients without DFU (Table 1).

To study the distribution of risk factors between men and women, we stratified all the studied population according to gender (Table 2). In the group of patients with DFU, there were a greater number of women with silent myocardial ischemia compared to men (28/63 (44.4\%) vs. 28/87 (32.2\%); $\mathrm{p}<0.05$ ) (Table 2). In the group of patients without DFU, there were a greater number of men with silent myocardial ischemia compared to women $(10 / 47(21.3)$ vs. $2 / 43(4.7 \%)$; p < 0.05) (Table 2).

Table 3 presents the number of patients with silent myocardial ischemia, in the studied groups, according to the presence or absence of DFU. Logistic regression analysis demonstrated that the odds ratio of having silent myocardial ischemia was 2.96 in women with DFU, 0.18 in women without DFU and 1.75 in men with DFU compared to men without DFU (Table 4).

\section{Discussion}

The main finding of the present study was that silent myocardial ischemia was more prevalent in women than in men with DFU and in men than in women without DFU. Likewise the odds ratio of having silent myocardial ischemia was 2.96 in women with DFU, 0.18 in women without DFU and 1.75 in men with DFU compared to men without DFU. This is the first report of the greater value of DFU in the prediction of silent myocardial ischemia in women with type 2 diabetes.

Women with type 2 diabetes have an increased risk of mortality from cardiovascular disorders compared to men [14]. Hence the sex difference seen in mortality from coronary heart disease in general population is abolished in type 2 diabetes [15]. The traditional risk factors for coronary heart disease such as hypertension, elevated serum cholesterol, smoking habit and diabetes dyslipidemia [16], do not explain the excessive prevalence of coronary heart disease

\begin{tabular}{|c|c|c|c|c|}
\hline & \multicolumn{2}{|c|}{ Without Diabetic foot ulcer $(\mathrm{N}=90)$} & \multicolumn{2}{|c|}{ With Diabetic foot ulcer $(n=150)$} \\
\hline & Women $(n=43)$ & Men $(n=47)$ & Women $(n=63)$ & Men $(n=87)$ \\
\hline Age (years) & $59.13 \pm 1.3$ & $58.25 \pm 1.93$ & $53.77 \pm 3.65$ & $56.11 \pm 2.24$ \\
\hline Diabetes Duration (years) & $5.42 \pm 0.97$ & $7.86 \pm 2.09$ & $13.67 \pm 2.24$ & $12.91 \pm 1.48$ \\
\hline HbA1C (\%) & $8.11 \pm 0.40$ & $7.55 \pm 0.204$ & $8.69 \pm 0.54$ & $9.13 \pm 0.52$ \\
\hline Triglyceride (mg/dl) & $178.86 \pm 10.13$ & $138.20 \pm 18.94^{*}$ & $186.29 \pm 24.64$ & $209.16 \pm 41.33$ \\
\hline Cholestrole (mg/dl) & $196.89 \pm 7.70$ & $179.6 \pm 9.93$ & $196.29 \pm 10.40$ & $180.50 \pm 9.28$ \\
\hline LDL-C (mg/dl) & $102.79 \pm 6.26$ & $114.13 \pm 11.36$ & $110.93 \pm 8.77$ & $97.28 \pm 7.78$ \\
\hline HDL-C (mg/dl) & $51.27 \pm 3.08$ & $48.00 \pm 2.89$ & $43.75 \pm 3.85$ & $41.00 \pm 2.21$ \\
\hline Creatinine (mg/dl) & $1.00 \pm 0.056$ & $1.11 \pm 0.09$ & $1.64 \pm 0.59$ & $1.22 \pm 0.071$ \\
\hline Systolic Blood Pressure (mmHg) & $145.75 \pm 5.75$ & $144.44 \pm 6.63$ & $126.25 \pm 5.71$ & $147.10 \pm 6.73^{*}$ \\
\hline Diastolic Blood Pressure $(\mathrm{mmHg})$ & $87.33 \pm 2.53$ & $87.7 \pm 2.77$ & $72.08 \pm 4.32$ & $92.52 \pm 2.79^{*}$ \\
\hline Silent myocardial ischemia (n, \%) & $2(4.7 \%)$ & $10(21.3 \%)^{*}$ & $28(44.4 \%)$ & $28(32.2 \%)^{*}$ \\
\hline
\end{tabular}

Variables distributed normally are expressed as Mean \pm Standard Error of Mean (SEM) otherwise, number and percent. Independent sample $t$ test was employed to compare quantitative variables between men and women. ${ }^{*}: \mathrm{P}<0.05,{ }^{*}: \mathrm{P}<0.01$, when comparing women with men in each group.

Table 2: Demographic and biochemical characteristics of patients with and without diabetic foot ulcer, stratified according to gender.

\begin{tabular}{|c|c|c|c|c|c|c|c|}
\hline & & \multicolumn{6}{|c|}{ Presence of diabetic foot ulcer } \\
\hline & & \multicolumn{2}{|c|}{ All patients $(n=240)$} & \multicolumn{2}{|l|}{ Women $(n=106)$} & \multicolumn{2}{|l|}{ Men $(n=134)$} \\
\hline \multirow{4}{*}{ Silent Myocardial Ischemia } & Odds Ratio & \multicolumn{2}{|c|}{$3.8[2.1-9.3](p<0.001)$} & \multicolumn{2}{|c|}{$16.5[3.6-73.7](p<0.001)$} & \multicolumn{2}{|c|}{$1.7[0.7-4.3](p=0.07)$} \\
\hline & & Negative $(n=90)$ & Positive $(n=150)$ & Negative $(n=43)$ & Positive $(n=63)$ & Negative $(n=47)$ & Positive $n=87$ ) \\
\hline & Negative $(n=172)$ & 78 & 94 & 41 & 35 & 37 & 59 \\
\hline & Positive $(n=68)$ & 12 & 56 & 2 & 28 & 10 & 28 \\
\hline
\end{tabular}

Table3: The odds ratio of having silent myocardial ischemia according to the presence or absence of diabetic foot ulcer in men, women and all studied population.

\begin{tabular}{|l|l|l|l|l|}
\hline & P value & Odds Ratio & \multicolumn{2}{|l|}{} \\
\hline Women with Diabetic Foot & & Lonfidence interval for Odds Ratio & Lower \\
\hline Women without Diabetic Foot & 0.013 & 2.960 & 1.256 \\
\hline Men with Diabetic Foot & 0.034 & 0.180 & 0.037 \\
\hline
\end{tabular}

Table 4: The odds ratio of having silent myocardial ischemia in different groups in comparison with men without diabetic foot ulcer; ulcer adjusting for HbA1c, HDL-C and diabetes duration. 
among women with diabetes $[17,18]$. Interestingly we showed that the presence of DFU is a significant predictor of silent myocardial ischemia in women only. These results raise the question whether there are different conditions in type 2 diabetic men and women that lead to diabetic complications.

Neuropahy, angiopathy and immunopathy are the key components responsible for DFU complications [19,20]. In 1987, Borch-Johnsen et al. described a male preponderance for the development of severe microvascular complications [21]. It is shown that nitric oxide (NO) bioavailability and $\mathrm{NO}$ responsiveness are greater in women than in men with sickle cell disease [22]. In the forearm circulation, stimulated endothelium dependent vasodilation is greater in female than male patients with diabetes [23]. Consistently Schneider et al. showed that $\mathrm{NO}$ availability in the renal circulation is greater in female than in male patients with type 2 diabetes [24]. On the other hand impairment of the microcirculation is believed to play a prominent role in the development of neuropathy $[25,26]$. It is shown that vasodilatory response of the cutaneous microcirculation of the foot is lower than that of the forearm in healthy subjects and that it progressively worsens in diabetic patients, being lower in patients with neuropathy [27]. Studies suggest that micro-vascular impairment is an early predictor of vascular disease, both in diabetic and non-diabetic patients $[28,29]$ We therefore concluded that women are usually protected against peripheral arterial disease; and as a consequence are protected against diabetic neuropathy. So once deleterious conditions are strong enough to result into DFU in women with type 2 diabetes, they have had their harmful effect on coronaries long before. In consistent with this hypothesis, Aaberg et al. showed that men with type 2 diabetes develop neuropathy earlier than did the women [30]. Dinh et al. showed a lower risk of developing DFU in women with type 2 diabetes, as a result of less severe neuropathy, increased joint mobility, and lower foot pressures [31]. Height is one of the main predictors for development of neuropathy [32]. As men are taller than women on average, it could be concluded that they are more vulnerable to develop diabetic neuropathy and foot ulcer disease as a consequence. Consistently Dinh et al. showed that once neuropathy or other risk factors are established, women have the same risk of developing foot ulcerations as men [31]. Similar to our findings; Forst et al. showed that limited joint mobility is significantly correlated with intima media thickness and early atherosclerosis only in women with type 1 diabetes, whereas these complications were similarly distributed in male counterparts [33].

On the other hand this may be due to the deleterious role of estrogen in women with type 2 diabetes. White et al. suggested that diabetic state is associated with estrogen-stimulated production of superoxide and a reduced level of NO within the vasculature [34]. Hidden confounders' for example life style differences between men and women that have not been included in the studied variables may account for the difference as well. Consistently Larkin et al. suggested that risk reducing measures such as taking medications; are underused in women with both type 1 and type 2 diabetes [35]. Furthermore cigarette smoking, which is 5 times more prevalent among Iranian men compared to women [10], is associated with reduced peripheral microvascular responses to both endothelial and smooth muscle cell stimulation [36], as well as blunted basal and stimulated NO bioactivity [37].

The occurrence of risk factors for the progression of DFU depend on metabolic control [38]. Age, BMI, blood pressure, lipid profile and
HbAlc did not differ between both sexes at the time of the examination, so it is unlikely that our results are confounded by differences in metabolic control. However, we could not refer to earlier metabolic parameters of our patients, so we could not rule out that the long-term metabolic control could have differed between the men and women.

The limitation of the study are those inherent in a cross sectional analysis which preclude the determination of the direction of causality. Moreover we could not measure transcutaneous oxygen pressure as this instrument was not available in our hospital. So the neuroischemic foot ulcerations may play an importance role in these findings and may have confounded our results. This may imply that peripheral artery disease may be the real predictor of SMI in women. However we took advantage of a relatively large sample size and close similarity between groups in most of the confounding variables. Furthermore silent myocardial ischemia was diagnosed with rest-dipyridamole SPECT, which is the most sensitive non invasive screening test for the detection of silent myocardial ischemia in patients with type 2 diabetes according to the guidelines of American College of Cardiology [13] We did not used dobutamine stress echography as it is not as sensitive as rest-dipyridamole SPECT and we would miss the patients with silent myocardial ischemia [39]. Silent myocardial ischemia was not confirmed by angiography, due to ethical limitations.

In conclusion we showed that women with DFU are at an increased risk of having silent myocardial ischemia, compared to male counterparts. In a recent study by Gazzaruso and collabolators, erectile dysfunction was considered as an early marker of silent myocardial ischemia in men with type 2 diabetes [40]. Considering the fact that about $40 \%$ of patients with asymptomatic coronary artery disease are missed on the basis of current guidelines [41], we suggest diabetic foot ulcer as an early and sensitive risk factor, predicting silent myocardial ischemia in women with type 2 diabetes. Considering the impact of sex steroid hormones on metabolic risk factors, we suggest that diabetes induced complications are mediated by different pathways in men and women.

\section{References}

1. Malmberg K, Yusuf S, Gerstein HC, Brown J, Zhao F, et al. (2000) Impact of diabetes on long-term prognosis in patients with unstable angina and nonQ-wave myocardial infarction: results of the OASIS (Organization to Assess Strategies for Ischemic Syndromes) Registry. Circulation 102: 1014-1019.

2. Cosson E, Attali JR, Valensi P (2005) Markers for silent myocardial ischemia in diabetes. Are they helpful? Diabetes Metab 31: 205-213.

3. Frye RL, August P, Brooks MM, Hardison RM, Kelsey SF, et al.( 2009) A randomized trial of therapies for type 2 diabetes and coronary artery disease. N Engl J Med 360: 2503-2515.

4. Wackers FJ, Chyun DA, Young LH, Heller GV, Iskandrian AE, et al.(2007) Resolution of asymptomatic myocardial ischemia in patients with type 2 diabetes in the Detection of Ischemia in Asymptomatic Diabetics (DIAD) study. Diabetes Care 30: 2892-2898.

5. Faglia E, Manuela M, Antonella Q, Michela G, Vincenzo C, et al.(2005) Risk reduction of cardiac events by screening of unknown asymptomatic coronary artery disease in subjects with type 2 diabetes mellitus at high cardiovascular risk. an open-label randomized pilot study. Am Heart J 149: e1-e6.

6. Verhave JC, Hillege HL, Burgerhof JG, Navis G, de Zeeuw D, et al. (2003) Cardiovascular risk factors are differently associated with urinary albumin excretion in men and women. J Am Soc Nephrol 14: 1330-1335.

7. De Cosmo S, Minenna A, Ludovico O, Mastroianno S, Di Giorgio A, et al. (2005) Increased urinary albumin excretion, insulin resistance, and related 
Citation: Jenab Y, Morteza A, Nozari Y, Farokhian A, Ardekani JM, et al. (2011) Diabetic Foot Ulcer is a Significant Predictor of Silent Myocardial Ischemia in Women with Type 2 Diabetes. J Diabetes Metab 2:161. doi:10.4172/2155-6156.1000161

Page 5 of 5

cardiovascular risk factors in patients with type 2 diabetes: evidence of a sexspecific association. Diabetes Care 28: 910-915

8. Brown WV (2008) Microvascular complications of diabetes mellitus: renal protection accompanies cardiovascular protection. Am J Cardiol 102: 10L-3L.

9. Kalaitzidis R, Bakris G (2009) Pathogenesis and treatment of microalbuminuria in patients with diabetes: the road ahead. J Clin Hypertens (Greenwich) 11: 636-643.

10. Meysamie A, Ghaletaki R, Haghazali M, Asgari F, Rashidi A, et al. (2009) Pattern of tobacco use among the Iranian adult population: results of the national Survey of Risk Factors of Non-Communicable Diseases (SuRFNCD-2007). Tob Control 19: 125-128.

11. Jeffcoate WJ, MacFarlane RM, EM Fletcher (1993) The description and classification of diabetic foot lesions. Diabet Med 10: 676-679.

12. Armstrong DG, Lavery LA, Harkless LB (1998) Validation of a diabetic wound classification system. The contribution of depth, infection, and ischemia to risk of amputation. Diabetes Care 21: 855-859.

13. Widding A, Hesse B, Gadsboll N (1997) Technetium-99m sestamibi and tetrofosmin myocardial single-photon emission tomography: can we use the same reference data base? Eur J Nucl Med 24: 42-45.

14. Szmuilowicz ED, Stuenkel CA, Seely EW (2009) Influence of menopause on diabetes and diabetes risk. Nat Rev Endocrinol 5: 553-558.

15. Kragelund C, Kober L, Faber J, Steffensen R, Hildebrandt P, et al.( 2007) Metabolic syndrome and mortality in stable coronary heart disease: relation to gender. Int J Cardiol 121: 62-67.

16. Mooradian AD (2009) Dyslipidemia in type 2 diabetes mellitus. Nat Clin Pract Endocrinol Metab 5:150-159.

17. Njelekela MA, Mpembeni R, Muhihi A, Mligiliche NL, Spiegelman D, et al. (2009) Gender-related differences in the prevalence of cardiovascular disease risk factors and their correlates in urban Tanzania. BMC Cardiovasc Disord 9:30.

18. Legato MJ, Gelzer A, Goland R, Ebner SA, Rajan S, et al. (2006) Genderspecific care of the patient with diabetes: review and recommendations. Gend Med 3: 131-158.

19. Ward KA, Dellacorte MP, Grisafi PJ (1993) Pathophysiology of diabetic neuropathy. J Am Podiatr Med Assoc 83: 149-152.

20. Silva AM, Schaan BD, Signori LU, Plentz RD, Moreno H, et al. (2010). Microalbuminuria is associated with impaired arterial and venous endotheliumdependent vasodilation in patients with type 2 diabetes. J Endocrinol Invest. 33: 696-700.

21. Borch-Johnsen K, Nissen H, Salling N, Henriksen E, Kreiner S,et al. (1987) The natural history of insulin-dependent diabetes in Denmark: 2. Long-term survival--who and why. Diabet Med 4: 211-216.

22. Gladwin MT, Schechter AN, Ognibene FP, Coles WA, Reiter CD, et al. (2003) Divergent nitric oxide bioavailability in men and women with sickle cell disease. Circulation 107: 271-278

23. Chan NN, Vallance P, Colhoun HM (2003) Endothelium-dependent and -independent vascular dysfunction in type 1 diabetes: role of conventional risk factors, sex, and glycemic control. Arterioscler Thromb Vasc Biol 23: 10481054.

24. Schneider MP, Ritt M, Raff U, Ott C, Schmieder RE, et al. (2009) Gender is related to alterations of renal endothelial function in type 2 diabetes. Nephrol Dial Transplant 24: 3354-3359.

25. Tesfaye S, Harris N, Jakubowski JJ, Mody C, Wilson RM, et al.(1993) Impaired lood flow and arterio-venous shunting in human diabetic neuropathy: a novel technique of nerve photography and fluorescein angiography. Diabetologia 36: $1266-1274$

26. Tesfaye S, Malik R, Ward JD (1994) Vascular factors in diabetic neuropathy. Diabetologia 37: 847-854.

27. Arora S, Smakowski P, Frykberg RG, Simeone LR, Freeman R (1998)
Differences in foot and forearm skin microcirculation in diabetic patients with and without neuropathy. Diabetes Care 21: 1339-1344.

28. Rossi M, Carpi A, Galetta F, Franzoni F, Santoro G, et al. (2006) The investigation of skin blood flowmotion: a new approach to study the microcirculatory impairment in vascular diseases? Biomed Pharmacother 60 $437-442$.

29. Urbancic-Rovan V, Bernjak A, Stefanovska A, Azman-Juvan K, Kocijancic A et al.(2006). Macro- and microcirculation in the lower extremities--possible relationship. Diabetes Res Clin Pract 73: 166-173.

30. Aaberg ML, Burch DM, Hud ZR, Zacharias MP (2008) Gender differences in the onset of diabetic neuropathy. J Diabetes Complications 22: 83-87.

31. Dinh T, Veves A (2008) The influence of gender as a risk factor in diabetic foo ulcerationi. Wounds 20: 127-131.

32. Cohen JA, Jeffers BW, Faldut D, Marcoux M, Schrier RW, et al. (1998) Risks for sensorimotor peripheral neuropathy and autonomic neuropathy in non-insulindependent diabetes mellitus (NIDDM). Muscle Nerve 21: 72-80.

33. Frost D, Beischer W (2001) Limited joint mobility in type 1 diabetic patients: associations with microangiopathy and subclinical macroangiopathy are different in men and women. Diabetes Care 24: 95-99.

34. White RE, Gerrity R, Barman SA, Han G (2010)Estrogen and oxidative stress: A novel mechanism that may increase the risk for cardiovascular disease in women. Steroids75: 788-793.

35. Larkin ME, Backlund JY, Cleary P, Bayless M, Schaefer B, et al (2010) Disparity in management of diabetes and coronary heart disease risk factors by sex in DCCT/EDIC. Diabet Med 27: 451-458.

36. Edvinsson ML, Andersson SE, Xu CB, Edvinsson L (2008) Cigarette smoking leads to reduced relaxant responses of the cutaneous microcirculation. Vasc Health Risk Manag 4: 699-704.

37. Butler R, Morris AD, Struthers AD (2001) Cigarette smoking in men and vascular responsiveness. Br J Clin Pharmacol 52: 145-149.

38. Vukovic J, Dumic M, Radica A, Filipovic-Grcic B, Jovanovic V, et al.(1996) Risk factors for expression and progression of limited joint mobility in insulindependent childhood diabetes. Acta Diabetol 33: 15-18.

39. Libby P, Robert Bonow, Douglas Zipes, Douglas Mann (2007) Braunwald's Heart Disease, A Textbook of Cardiovascular Medicine.

40. Gazzaruso C, Coppola A, Montalcini T, Valenti C, Garzaniti A, et al.(2011) Erectile dysfunction can improve the effectiveness of the current guidelines for the screening for asymptomatic coronary artery disease in diabetes. Endocrine 40: $273-279$

41. Wackers FJ, Young LH, Inzucchi SE, Chyun DA, Davey JA, et al.(2004) Detection of silent myocardial ischemia in asymptomatic diabetic subjects: the DIAD study. Diabetes Care 27: 1954-1961. 